\title{
«LOS ÚLTIMOS DÍAS DE DIEGO DE LEÓN EN NICOMEDES PASTOR DÍAZ Y EN GALDÓS»
}

\author{
María José Alonso Seoane \\ Universidad Complutense de Madrid
}

\section{Nicomedes Pastor Díaz y Galdós.}

Aun desde un primer acercamiento a los Episodios Nacionales es muy fácil ver que el deseo de Galdós no es sólo transmitir la historia de España, desde su personal interpretación, en forma novelada, sino lograr también que los personajes, escenarios, costumbres, lenguaje, todos sus elementos, tengan color de época; y se vean $-\mathrm{y}$, a ser posible, «se oigan»- los acontecimientos históricos y la vida del momento, tal como los vieron entonces y como fueron referidos por sus contemporáneos. Para este propósito, Galdós utilizó los textos más cercanos a los hechos que pudo encontrar —además de otros materiales-; y en esta tarea de reproducción de un ambiente en torno a un suceso histórico, se sirvió, en ocasiones, de la obra de un escritor poco conocido ahora, hombre importante en su tiempo: Nicomedes Pastor Díaz. El escritor gallego aparece como personaje en los Episodios Nacionales y, como novelista, interesó también a Galdós, que se sirve de su obra De Villahermosa a la China como intertexto para alguno de sus Episodios, fundamentalmente en Las tormentas del $48^{1}$. En cuanto a sus obras históricas, a pesar de la diferencia de ideas existente entre ambos, Galdós no podía desperdiciar las impresiones de primera mano que le ofrecía Pastor Díaz ${ }^{2}$;

1 Trato este asunto en mi comunicación al Congreso Galdosiano «Centenario de Fortunata y Jacinta» (Madrid, 23 al 28 de nov. de 1987) «Nicomedes Pastor Díaz y Galdós: De Villahermosa a la China en los Episodios Nacionales» en Galdós. Centenario de «Fortunata y Jacinta» (1887-1987). Actas, Madrid, Facultad de Ciencias de la Información, Universidad Complutense, 1989, pp, 101-113.

2 Sigo la costumbre de utilizar 'Pastor', segundo nombre del escritor, como apellido, tal como se hizo en la época, como señala F. de la Puente Apecechea (Prólogo general a las Obras Completas de Nicomedes Pastor Díaz). 
textos que, por otra parte habían sido utilizados por los historiadores importantes de la época, como Galdós conocía. Pastor Díaz, en efecto, no debía gustar demasiado - políticamente- a Galdós; pero, como liberal, aunque moderado, podía presentar una versión conforme a sus ideas frente a los defensores del carlismo; y, como puritano, atenuaba las diferencias que habría con el enfoque progresista de los textos novelescos galdosianos. Pastor Díaz, que como personaje de los Episodios carece de interés especial, ofrece a Galdós, en sus textos históricos, versiones preciosas de los hechos - en concreto, en la biografía de Diego de León- por su rigurosa coetaneidad, que, dando por supuestas otras cualidades, facilitaba un marcado tono de época en su visión de la historia y en la misma materialidad de sus palabras.

Galdós: historia y novela.

Se considere o no como lo más interesante de los Episodios Nacionales la referencia a la historia, es eso lo específico de estas obras galdosianas y, con frecuencia, la referencia se hace estrictamente a un texto histórico determinado, con el que el escritor canario establece un diálogo intertextual. Ciertamente, a medida que avanzan los Episodios, y de manera especial en la tercera serie, «lo histórico y lo particular humano aparecen mucho más sabiamente combinados» ${ }^{3}$, pero el sentido de los Episodios es dar historia de España a los lectores de novela, en forma de novela; y, a veces, esa historia - que muchas otras procede de relatos orales o de un conjunto de datos dispersos en obras generales - tiene un correlato concreto que procede como intertexto definido del texto galdosiano. Berkowitz, Hinterhäuser, Cardona, etc., dan datos de los libros que Galdós ha podido manejar para la documentación histórica de los Episodios; en lo referente a Pastor Díaz, está probado que Galdós utilizó las semblanzas de Diego de León y de Cabrera que aquél escribió para la Galería de Españoles celebres contemporáneos ${ }^{4}$. En relación a Cabrera, Galdós utilizó otros materiales para el trazado de su figura en La campaña del Maestrazgo, pero sin duda tuvo presente la importancia, en su momento, de la biografía de Pastor Díaz; biografía a la que remiten otras obras históricas posteriores, más o menos cercanas, y que el propio Cabrera conocía y nada menos que citaba. Así aparece como conversación mantenida con el autor en el prólogo de la obra de Buenaventura de Córdoba, Vida militar y política de Cabrera, justificando sus procedimientos crueles con el fusilamiento

3 J. F. Montesinos, Galdós (III), Madrid, Castalia, 2. ed., 1980, pág. 18.

4 Cfr. R. Cardona, «Apostillas a Los «Episodios Nacionales» de B. P. G., de Hans Hinterhäuser», Anales Galdosianos, III, 1968, pág. 124. «En las páginas del Tomo 2\%, que corresponde al volumen 3 de la obra, Galdós escribe los siguientes nombres: Montes de Oca, General León, Conde de Ofalia, Navarrete, Cabrera, Bretón de los Herreros y Alcalá Galiano. Galdós utiliza de este tomo especialmente las semblanzas de Montes de Oca, General León y Cabrera». [Galería de Españoles célebres contemporáneos o biografías y retratos de todos los personajes distinguidos de nuestros días en las ciencias, en la política, en las armas, las letras y en las artes, publicadas por don Nicomedes Pastor Díaz y don Francisco de Cárdenas, 7 tomos encuadernados en 4. Madrid: Imprenta Sánchez, e Ignacio Boix, 1841-1845]. 
de su madre, hecho inhumano que condenaron los dos bandos. Córdoba, que escribe en 1844, transcribe las palabras de Cabrera: «Hasta mis enemigos me han hecho justicia en esta parte. Todos los periódicos de la época se levantaron contra tan bárbaro e inaudito atentado; y un escritor, a quien por cierto no debo grandes simpatías ${ }^{5}$, decía en 1842 ... Desde aquel momento Cabrera quedaba disculpado de todos sus horrores... muchas veces hemos temblado al discurrir de lo que hubiéramos sido capaces nosotros que nos tenemos por de costumbres blandas, instintos y hábitos de humanidad y dulzura, si hubieran fusilado a nuestra madre por el crimen de habernos dado la vida... Nosotros escuchábamos de boca de algunas personas pacíficas estas palabras terribles: yo hubiera hecho más si hubieran fusilado a mi madre ${ }^{6}$. Cabrera (o su transcriptor, Córdoba) cita de memoria el texto de Pastor Díaz en que éste comenta la muerte de María Griñó: «Desde aquel momento, Cabrera quedaba disculpado de todos sus horrores. El vértigo, el frenesí de matanza que le acometió no podría justificarse jamás, pero se explicaba y se comprendía. Muchas veces hemos temblado al discurrir que en circunstancias semejantes hubiéramos podido ser monstruos también. Nos hemos aterrado, cuando después de la sangrienta relación de los horrores cometidos en Aragón y Valencia, escuchábamos de boca de alguna persona pacífica y de condición suave, estas palabras terribles: 'Yo hubiera hecho más si hubieran fusilado a mi madre'.» (289).

Los ultimos días de Diego de León en la biografía de Pastor Díaz y en un fragmento galdosiano.

Pero el texto pastordista que deseo aquí analizar por extenso en relación a Galdós corresponde a la biografía de Diego de León, publicada en la Galería de Españoles célebres contemporáneos y, en concreto, a su última parte. En ella muestra Pastor Díaz admiración incondicional por la figura del general, describe sus hechos de guerra - verdaderas hazañas-y, por último, su participación en el golpe en el Palacio Real —que justifica-; y su condena y muerte, de héroe y már-

5 Sin duda, recordaba, entre otras cosas, la descripción del festín de Burjasot y los fusilamientos simultáneos que Pastor Díaz cuenta con horror y que Galdós traslada en los Episodios Nacionales (t. III, Madrid, Aguilar, 1986; ed. de F. C. Sainz de Robles, 2. ed., 1. reimpr., págs. 526-8. Todas las citas de Galdós se refieren a esta edición; en adelante, sólo indicaré la pág. o págs. entre paréntesis a continuación de la cita). No es lugar aquí para analizar la versión galdosiana del estremecedor relato, pero constituye uno de los pasajes de mayor intensidad emotiva de La campaña del Maestrazgo. El texto de Pastor Díaz puede verse en las Obras Completas, t. I, Madrid, Atlas, 1969, págs. 294-5 (citaré siempre por esta edición, señalando solamente, entre paréntesis, la pág. o págs. correspondientes). Sin duda también Cabrera apreciaría el esfuerzo de objetividad de Pastor Díaz con él, y la consideración positiva que en algunos aspectos le merece y que explícitamente expresa. El motivo de la sangre corriendo a los pies de los soldados carlistas mientras el vino saltaba en sus copas, en Burjasot, recogido por Pirala, procede, como éste indica, de Pastor Díaz; Cabrera también lo conocía y negaba (Cfr. A. Pirala, Historia de la guerra civil y de los partidos liberal y carlista, Madrid, 1890, t. III, págs. 863-4).

6 Buenaventura de Córdoba, Vida militar y política de Cabrera, Madrid, Eusebio Aguado, 1844, págs. IX-X. 
tir. Biografía muy bien escrita, muy literariamente. Galdós se fija sólo en la parte final, desde los preliminares del golpe a la ejecución de la sentencia. Como Galdós podía en cierta manera admirar a León y lastimarse de su suerte, no ofrece demasiadas dificultades la traslación de lo escrito por Pastor Díaz como intertexto de Los Ayacuchos.

Con toda soltura, Galdós pulveriza el texto de Pastor Díaz para darlo asimilado e integrado en el discurso de dos narradores opuestos —en ideas políticas, manera de ser y lenguaje- que relatan los hechos en sus cartas a Fernando Calpena: Mariano de Centurión y Serafín de Socobio. Con acierto afirma V. Lloréns que «Toda visión de Galdós adquiere inmediatamente configuración humana. La vida y el mundo se ofrece a sus ojos en forma personal. [...] Así también, en forma personal, ve Galdós la historia. [...] Si hasta la historia comercial la ve Galdós como algo personal y novelesco, claro está que no podía ver de otro modo la historia de la España moderna» ${ }^{7}$. Galdós narrativiza la historia ${ }^{8}$, resume el texto histórico, añade ocasionalmente datos procedentes de otras fuentes; se salta lo que no le interesa, aunque pudiera interesarle al narrador-personaje de turno, como es el caso de Socobio con respecto a las ideas religiosas de León ${ }^{9}$. En general, con los textos de los dos narradores -que en algunos tramos se recubren-Galdós ofrece una versión bastante fiel del texto pastordista, a la vez que recrea el estado de ánimo y la visión de los hechos que hubieron de darse, en más o menos, en su momentó, desde los dos puntos de vista que quiere reflejar: el de los progresistas y el de los moderados; aunque los dos narradores resulten poco adecuados y el texto noble de Pastor Díaz, en lo referente a los ideales y muerte de León, aparezca desfigurado, e incluso más en el de su correligionario, Socobio, en su tono beato y compungido. Sin duda este planteamiento responde a un deseo de ecuanimidad, aunque en este caso no se consiga por la voz de un narrador digno ${ }^{10}$ sino por el conjunto de los dos puntos de vista opuestos. Centurión y Socobio reflejan también, en su enfrentamiento personal, la división fraticida de España que no cesa en todo el período tratado por Galdós, bajo la que el escritor concibe en gran manera la historia de España y, consecuentemente, sus Episodios Nacionales.

7 V. Lloréns, «Historia y novela de Galdós», Cuadernos Hispanoamericanos, 1970-1, LXXXIV, pág. 80.

8 Cfr. G. Gullón, «Narrativizando la historia: La corte de Carlos IV», Anales Galdosianos, XIX, 1984, pág. 46.

9 No queda nada del explícito texto de Pastor Díaz en que da cuenta de la razón de la serenidad que mantuvo León en todo momento: «¿En donde bebió aquella resignación entera y apacible que da un carácter augusto a las horas de su desgracia? La bebió en el cumplimiento de los deberes que se había impuesto como militar y caballero; pero la bebió sobre todo en las inspiraciones de una religión sublime, sin cuyo bálsamo es árido hasta el heroísmo. León creía, León era religioso, para asemejarse en todo a un antiguo caballero. En sus últimos momentos miraba a la tierra como héroe y al cielo como cristiano; sobre su corazón se encontró una reliquia que le había acompañado en todos sus peligros; y el sacerdote que el acompañó hasta su muerte no puede recordar sin enternecimiento aquellos instantes en que tuvo arrodillado a sus plantas al mejor caballero de España» (272-3).

10 Cfr. G. Gullón, «Narrativizando la historia...». art. cit., págs. 45 y 50. 
Con anterioridad a los relatos epistolares de Centurión y Socobio, el narrador, en tercera persona, nos presenta el momento inicial del golpe, desde las voces y el punto de vista progresista y palaciego de la condesa de Mina y de Centurión, que contamina, aunque no siempre, su discurso. Vienen después las cartas a Calpena, en las que Centurión da instantáneas del golpe y prisión de León supone a Calpena informado más extensamente por un tercer comunicante, Nocedal - y un dato que, implícito en Pastor Díaz, remite, sin nombrarlo, al otro corresponsal de Calpena, Socobio: alguno de sus compañeros en funciones palatinas, se alegrarán por la muerte de León al serlo como mártir de la causa. Socobio, parte más interesada en el suceso, como moderado, narrará con mayor detenimiento -y mayor fidelidad al texto pastordista, aunque con emoción tan empalagosa que resulta ridícula-, la huída de León y sobre todo el proceso de su captura, juicio y muerte. Sin duda Galdós no utiliza la narración de Pastor Díaz como único y excluyente intertexto - aparte de su propia imaginación y libertad que demuestra - pero, desde luego, es inequívoca la filiación básica, de conjunto y en detalle, a la biografía pastordista; tan cercana a los hechos, en todos los sentidos, con lo que esto significa de interés primordial para Galdós.

La narración de Pastor Díaz, como es habitual en textos de carácter histórico, sigue el orden cronológico de los hechos en rasgos generales. También lo hacen los narradores ocasionales, que escriben a Calpena en fechas consecutivas, mientras se desarrolla el drama, y después de la muerte de León; solamente por excepción se altera el orden de aparición de algún fragmento del texto pastordista. Los textos correspondientes al golpe de los conjurados y a la detención y muerte de León, en Los Ayucachos, se desarrollan conforme al siguiente esquema, del que ya parte hemos adelantado.

Previa a la narración epistolar de los hechos, se expone la situación en Palacio en la noche del atentado (7 de octubre de 1841) y al día siguiente, en el capítulo III. Enlazando con la situación narrativa inicial de la novela, se le comunica a las augustas niñas la batalla en la escalera, la identidad de los conjurados, cuál era su objeto, y también su fracaso, huída y búsqueda. Todo ello desde la voz y el punto de vista - como señalamos- de la condesa de Mina y después de Centurión; en el tono infantil de la narración con que empieza la novela, recreando el mundo de los soles de inocencia, Isabel y su hermana, con una admirable polifonía de voces narrativas:

«Sorprendidas y aterradas quedáronse las dos niñas cuando la condesa de Mina entró en el dormitorio y les dijo que aquella noche había ocurrido en Palacio un suceso muy grave: nada menos que una batalla en la escalera, entre unos locos que querían entrar y subir, y los alabarderos que supieron cumplir y cortarles el paso. No podía doña Juana de Vega empequeñecer y desvirtuar la página histórica reduciéndola a las proporciones de un cuento de niños, y a las curiosas preguntas de la Reina y la Princesa contestó que los tales eran generales... ¿Quiénes? Precisamente los más nombrados, los héroes de la última guerra, los Concha, León, Pezuela..., y tras ellos, coroneles, oficiales, alguna tropa... Pero no creyeran las niñas que el intento de éstos era matarlas o hacerles daño material, no; el ciego designio que les había impulsado a tan grave atropello no era otro que coger a la Reina y a su hermanita y llevárselas con muchísimo respeto 
a donde pudieran proclamar caducada la ley que felizmente nos regía, y establecer nueva Regencia. ¡Locos, locos rematados! Pero en el pecado llevaban la penitencia, porque el plan se les deshizo desde que quisieron ponerlo en ejecución, y antes de amanecer ya había huído todos, escondiéndose cada cual donde pudo» (887-8).

Todos éstos son hechos que Pastor Díaz narra, pero vistos aquí desde el ángulo opuesto, en distintos sentidos: espacial, desde el interior de Palacio, y político, desde los presupuestos de aquellos a quienes, con el golpe, se iba a derrotar. Como en las cartas que siguen, Galdós muestra un muy logrado desarrollo imaginativo a partir del texto pastordista; y donde no llega la condesa de Mina, que sabe del honor de los conjurados, llega Centurión considerándoles capaces de regicidio cuanto todavía se busca a los huídos. De esta calumnia, que alcanzó a León, se hace eco en otro lugar (la biografía de Cabrera) de manera explícita, Pastor Díaz; aquí lo hace indirectamente, con palabras que Centurión, encendido progresista, elabora en sentido opuesto. Escribe Pastor Díaz:

«Volviose a trabar entonces el combate a principios de la noche, cuyo fuego aguantó León parapetado medio cuerpo en el umbral de una puerta. La idea de las angustias de la Reina contenía a aquellos hombres, si bien el nombre de León y de los jefes sublevados decía claramente a las augustas Niñas que sus mejores amigos eran los que estaban llamando por ellas en aquel trance. Además, aquella temeridad era inútil, porque la Reina había sido conducida por sus guardianes a la estancia más retirada del edificio [...] Verdad es que la Persona hubiera sido en poder de ellos la salvaguardia de sus vidas y de sus personas; verdad es que otros hombres hubieran intentado en aquel trance cuanto sugiere el valor de la desesperación en las almas cobardes. Pero León y sus compañeros no eran de esa clase de hombres» (265-6).

En la versión galdosiana, Centurión contesta a la reina y su hermana que le piden interceda para que las saquen de paseo:

«no se ocultará que la prudencia nos aconseja no proponer la salida de las Reales personas..., y menos hacia la Casa de Campo, donde, según la voz pública, se han ocultado más de cuatro pillos de los que anoche quisieron dar a la Patria un día de luto. Tomadas por retenes de tropa están todas las entradas y salidas de la Real posesión, y como los ilusos, por no darles otro nombre, que se esconden en aquellos matorrales han de hacer alguna barbaridad en el último rapto de su locura y desesperación, no es prudente andar por allí. Hace un ratito creímos oír tiros hacia aquella parte» (889) ${ }^{11}$.

Después comienzan las cartas. El 8 de octubre escribe Centurión a Calpena. Da por supuesto que éste está enterado de los sucesos por carta de Nocedal, y Centurión trata sólo brevemente y muy por encima de los preludios de la conju-

11 Escribe Pastor Díaz, hablando de la muerte en batalla del general Pardiñas: «Ahora hemos tenido dolorosos motivos para consolarnos de su triste pérdida. Al fin murió con gloria; sucumbió en el campo de batalla. Al recordar el temple de su carácter y sus ideas políticas, pensamos que, de haber vivido, hubiérase podido ver envuelto en la desgracia de otros generales [...] Podría haber muerto con el nombre de traidor como Borso, con la calumnia de regicida como León» (304). 
ración, para centrarse en lo que más le afecta: el ataque a Palacio. Abandona después el relato de Pastor Díaz para manifestar las protestas de los progresistas contra los moderados que permanecen en Palacio y los involucrados en la conjura; en concreto, se queja de Socobio, que es el otro informante de Calpena. El 12 de octubre hay carta de Socobio y Calpena. Consciente de que suministra datos para la historia, el cesante muestra su hostilidad hacia el Regente. Cuenta también el golpe de los conjurados y sobre todo la huída y prisión de Diego de León. Después, apartándose del texto de Pastor Díaz, divaga sobre las razones del fracaso, culpando a Ingleterra. Justifica el golpe por razones de caballerosidad con respecto al honor de las damas —en este caso, de María Cristina-, da noticia de la ejecución de Borso di Carminati en Zaragoza, etc. El 13 de octubre escribe Centurión a Calpena, una carta más extensa que la primera, en la que vuelve sobre los preliminares del golpe y los primeros momentos de éste, así como la prisión de León, a quien respeta, recubriendo en parte el relato de Socobio. El resto de la carta no tiene que ver con Diego de León, sino que se refiere por extenso a la Reina: sus travesuras y progresos, tipo de educación que necesita, etc. El 16 de octubre, una larga y sentida carta de Socobio da cuenta del final del drama de León. A pesar de que escribe «transido» de dolor, sigue fielmente, aunque desde su punto de vista y lenguaje correspondiente, el texto de Pastor Díaz, con el artificio - que Galdós utiliza alguna otra vez ${ }^{12}$ - de haber sido testigo presencial por su condición de hermano de la Paz y Caridad. Completa el desarrollo, insinuado en Pastor Díaz y novelado en Centurión, de la consideración de León como mártir. Continúa la carta, en fecha de 17 de octubre, separándose definitivamente del texto pastordista y perdiendo, quizá por eso, su condición de narrador un tanto llorón pero soportable, para convertirse en narrador absolutamente poco simpático - aunque no tan despreciable como Pipaón- que consigue el efecto contrario en su labor de ataque a los progresistas. Tampoco, a fin de cuentas, resultaba demasiado simpático Centurión, con sus gracias y expresiones extemporáneas, con lo que se consigue un cierto equilibrio en la versión de los dos narradorespersonajes, lo que probablemente era un objetivo buscado por Galdós. Entre el capítulo III y el VIII de Los Ayacuchos aparece trasladada toda la historia de Diego de León: el texto de la biografía de Pastor Díaz en su última parte.

Veamos algunos ejemplos del tratamiento que da Galdós al texto pastordista; ejemplos de los que previamente cabe decir que en todos encontramos, en diferentes grados, tres caracteres comunes: en todos, el autor implícito quiere transmitir la información que Pastor Díaz proporciona sobre el golpe y la muerte de León; en todos, se tiende a resumir el material original (a veces, varias páginas se condensan en una breve carta); por último, en todos se realiza la intertextualidad según la idiosincrasia, ideas políticas, mentalidad y, por supuesto, lenguaje, de cada narrador-personaje, así como en relación al desarrollo de los acontecimientos.

12 Estupiñá, en Fortunata y Jacinta, afirma haber visto ajusticiar a Merino, sobre el propio patíbulo, por ser él de la Paz y Caridad. 
La introducción en el tema, centrada no todavía en la figura de Diego de León, sino en los preparativos del golpe y su realización, se lleva a cabo con un resumen drástico de varias páginas de Pastor Díaz, absolutamente asimiladas y transformadas en este caso por Centurión, que recoge los extremos más importantes. Centurión mezcla el lenguaje oficial con su propia agermanada y burlesca manera de expresarse, filtrando el texto desde sus ideas opuestas a la posición de Pastor Díaz; aunque no deja de advertírsele cierta admiración por los sublevados:

[Pastor Díaz]

«Habían celebrado ya estos hombres comprometidos su acuerdo definitivo; habían hecho su resolución; estaban tomando sus últimas providencias, cuando he aquí que reciben aviso de que a cada uno de ellos les aguardaba en sus casas un oficial con órdenes del Gobierno para conducirlos inmediatamente a diferentes puntos de la Península. Espiados tiempo había por una tumba de agentes de policía, cada cual se había anticipado a sustraerse de manos del Gobierno». (263)

\section{[Galdós: Centurión]}

«Ilustre señor: A lo dicho anteriormente acerca del abortado crimen de lesa majestad y de lesa patria, debo añadir que días antes del ataque a Palacio llegó a las narices del Gobierno el olorcillo de la conjuración, y la Policía no cesaba de olfatear el rastro de los caballeros del orden, que, escondidos unos en misteriosas casas, disfrazados otros en la calle, daban los pasos y ponían los puntos para coordinar su infamia». (897)

Y más adelante:

[Pastor Díaz]

«Era el 7 de octubre. Por la tarde sonaron tiros en el cuartel del Soldado; al anochecer sonaron descargas en Palacio y tembló Madrid. Los tiros eran de los soldados del primer regimiento de la Guardia a sus oficiales, quienes, apenas sabedores de haber sido separados del cuerpo aquella misma mañana, se encaminaban los más desde el café de San Luis hacia su cuartel, y eran recibidos a balazos». (263)

\section{[Galdós: Centurión]}

«A tientas, adivinando la conspiración antes que conociéndola, andaba en aquellos días el Gobierno, y en su perplejidad acertó con una de las medidas tomadas el 7 por la mañana. Separada toda la oficialidad del primero de la Guardia, y ascendidos a oficiales los sargentos, cuando los del orden se presentan en el cuartel para sacar a la tropa les reciben a tiros... He aquí el primer contratiempo de los ternes de doña María, principio de su desconcierto y de las tonterías que hicieron en la noche que yo llamo de San Marcos». (897)

Por lo demás, Centurión resume así el plan de la conjunción, las circunstancias en que se desarrolla el golpe y la valiente decisión de León y Pezuela de unirse a los que peleaban dentro de Palacio, cercado ya por las tropas leales a Espartero, que Pastor Díaz, con tono objetivo y sobrio, había relatado extensamente: 


\section{[Galdós: Centurión]}

«El jefe del movimiento debía ser León. Habían concertado que aquí se diese el grito que secundasen en las provincias O’Donell, Borso, Piquero y Urbistondo... Anticípanse los de allá; los de aquí dudan, no se determinan; les falta la Guardia; ciego se lanza Concha a Palacio; León tiene celos, creyendo que el otro gachó se le quiere poner por delante y oscurecerle; corriendo mil peligros, y cuando tropa y milicianos están ya sobre las armas, montan a caballo León y Pezuela y se plantan en Palacio, sabiendo que van a una muerte segura. Aquí de los crúos...» (897)

Apenas se recogen en la novela los avatares de la huída y detención de León, hecho del que dan cuenta los dos narradores. Paradójicamente - aunque no tanto, pues su buen corazón comienza a dejarse ver- es Centurión el que recoge el dato, tan favorable al héroe, de que pudo huir y no lo hizo, consignado por Pastor Díaz:

\section{[Pastor Díaz]}

«Los húsares permanecieron gran rato silenciosos; pero luego se soltaron en alabanzas y en lástimas del general, y hay quien dice que si él lo hubiese oído, fácil le fuera volver grupa y arrastraslos consigo a donde quisiese. Tal es, a lo menos, el testimonio del comandante Laviña, el cual ha dicho, y es de creer, que instó al general a la fuga, ofreciéndose a seguirle. La conducta de León sólo se explica por dos cosas: porque, como él mismo dijo después, no sabía huir, y porque no temía la suerte que le aguardaba». (267)

\section{[Galdós: Centurión]}

«Lo demás es ya público y notorio. León se entregó en Colmenar a los húsares de La Princesa, mandados por Laviña, y aunque éste quiso facilitarle la fuga, el nuevo Cid rehusó aceptarla. Dijo que no había huído nunca y es verdad». (897)

Socobio, con su voz, muestra también en sus cartas su personalidad, y de igual manera que Centurión, desde el lado opuesto, tiende a facilitar la comprensión del texto pastordista, extrayendo conclusiones al reformular, parafraseándolo, el intertexto:

\section{[Pastor Díaz]}

«Cuando los húsares llegaron a las puertas de Madrid con su prisionero, se presentó un oficial encargado por el duque de la Victoria de entregarse de su persona y conducirle al cuartel de Santo Tomás. [...] le preguntó, algo extrañado, el oficial: '¿Al cuartel del Santo Tomás?‘. 'Al cuartel de Santo Tomás', repuso el duque. '¿Al de Nacionales?'. 'Al de Nacionales'. La Regencia quería compartir con la revolución aquella responsabilidad». (267)

\section{[Galdós: Socobio]}

«Yo he llorado como un niño al saber que el moderno Cid era conducido a esta Corte y encerrado en Santo Tomás como el último vocinglero de los clubs a quien el hambre y la ignorancia convierten en furibundo maratista». (895) 
Pastor Díaz, dentro de un general deseo de objetividad y concisión, manifiesta a veces su emotividad, especialmente al describir el estado de ánimo de la población madrileña en torno a la suerte de León, a punto de ser juzgado. En el texto galdosiano, como en otras ocasiones, se refleja la misma situación, pero apenas se trasluce el apasionamiento oratorio con que se expresa Pastor Díaz:

\section{[Pastor Díaz]}

«Pero como quiera que la inmensa mayoría de todas las clases de la sociedad y del pueblo, aún aquellas que no simpatizaban con la causa que en él había sido vencida, como quiera, decimos, que la inmensa mayoría de Madrid y de España hubieran deseado para León la libertad y la vida, difícil sería determinar si en los partidos vencedores no hubo muchos hombres que se alegrasen en el fondo de su corazón de lo que sucedía; [...] No vayáis a preguntárselo hoy a la mayor parte de ellos, porque la justicia ejercida con León es una de aquellas justicias de que hasta los más ciegos y hasta los más perversos se arrepienten y se disculpan: no vayáis a preguntárselo hoy, porque os responderán, porque os jurarán que no; pero, ¿lo dijeron, lo juraron entonces? [...] La mayor parte de las gentes se hacía la ilusión de que León no moriría, y algunos hombres de la situación tenían bastante hipocresía para sostener y aparentar ellos mismos tal esperanza; pero los unos se engañaban en el ardor de su deseo, y los otros eran hipócritas en la expresión del suyo. ¿Morirá? ¿Morirá? He aquí la pregunta que todo el mundo se hacía, y la respuesta que todo el mundo se daba». (267)

[Galdós: Socobio]

«Por Madrid se corre que no le aplicarán la última pena. Los que el día de su captura pedíamos su cabeza andamos ahora compadecidos, que esto es condición de españoles. Si bien se mira, no fue Diego de León el más culpable; si a mí me dejaran aplicar justicia en este caso, mandaría pasar por las armas a los paisanos que han venido de París con este fregado y a las cabezas pensantes del moderantismo». (897)

Sin duda, este caso da idea de las tensiones entre lo expresado por Pastor Díaz y el autor de la novela, que en ocasiones, como hemos visto, llega a silenciar datos y calificativos que no le interesan; silencios a veces significativos, como la acusación explícita que Pastor Díaz hace a Argüelles y que ni Socobio, pensando como piensa, concreta. Pastor Díaz relata los distintos intentos de indulto que se llevaron a cabo al saber la condena a muerte; entre ellos, las gestiones de la marquesa de Zambrano en Palacio:

\section{[Pastor Díaz]}

«Mientras en la prisión se representaban estas escenas de dolor y de grandeza, en el Palacio Real y en el palacio de Buena-Vista se habían representado otras escenas que la historia no sabrá cómo calificar. La señora marquesa de Zambrano se había arrojado a los pies de la Reina y pedídola su alta intercesión para con el Regente; la Reina escribió una carta al general Espartero, pero don Agustín Argüelles, el anciano de los odios políticos, vedó aquella acción generosa a su augusta pupila». (273) 
En el texto galdosiano queda:

[Galdós: Socobio]

«De nada valieron los esfuerzos de tantas personas sensibles y honradas para enternecer el corazón de piedra del señor Duque-Regente. La marquesa de Zambrano, madre política del héroe condenado, se arroja a los pies de Su Alteza; la propia Doña Jacinta intercede con lágrimas. La Reina quiere escribir una cartita al tirano, y no la dejan». (900)

En general, a medida que avanza la causa de León y hasta el desenlace, el texto de Pastor Díaz se transmite con mayor fidelidad, para dar noticia más amplia de lo ocurrido históricamente. Incluso se recoge no sólo la narración de los hechos sino los comentarios de Pastor Díaz:

[Pastor Díaz]

«A la una en punto de la mañana salió el general León del cuartel de Santo Tomás, y subió con su defensor y su confesor en el coche que le esperaba. Llevaba en aquella postrera solemnidad también el uniforme de húsar, el uniforme de los que él había conducido en otro tiempo a Villarrobledo, y a él le habían conducido ahora a Madrid; y queriendo ofrecerse como en triunfo a la muerte, se había puesto al pecho hasta la última de sus cruces. La expresión de su fisonomía eran la severidad y la calma; [...] El pueblo le veía pasar en silencio; sólo se oían los sollozos de las mujeres y el son de los tambores. Pero ¡oh! ¡cuán miserables le debían parecer los hombres al general León en aquel trance! Allí, cubriendo la carrera, tristes y dolientes, sí, pero contemplando inmóviles el sacrificio, estaban las tropas que debieron formar a su voz el día 7. ¿Cómo iban ellas mismas a apuntar a aquel corazón, cuyo latido las había sostenido tantas veces en el campo; a aquella cabeza que habían visto tantas veces descollar orgullosamente entre los escuadrones y los batallones precipitados sobre el enemigo? ¿Cómo iban a tender a sus pies, con sus propios fusiles, al general a quien iban a aclamar ocho días antes por jefe suyo, ni qué justicia era aquella, ni militar, ni política, ni de ninguna especie, que iban a ejecutar [...]?» (274)

[Galdós: Socobio]

«La curiosidad llevóme de nuevo a las lúgubres salas de Santo Tomás, y si hubiera tardado un minuto no habría visto salir al mártir para el lugar del suplicio. Me agregué a mis compañeros de la Hermandad que iban en el último coche, y seguí la fúnebre comitiva. De gran uniforme, cubierto el pecho de cruces, iba el General en carretela descubierta, a su lado el sacerdote, enfrente Roncali... ¿Qué pensaría el hombre que llevaban a ajusticiar cuando, al pasar la vista por las tropas que cubrían la carrera, reconoció los cuerpos que se habían comprometido con él para el movimiento del 7? [...] Personas hubo (y así me lo han dicho más de cuatro) que no se persuadieron de la verdad del fusilamiento hasta que sonaron los tiros. La Milicia Nacional, que formaba en la Plaza de la Cebada (donde hoy está Novedades), le vio pasar con pena». (901-2)

Sin embargo, la personalidad del narrador novelesco se mantiene, resumiendo en tono vulgarizador, el texto noble de Pastor Díaz, dando, devaluado, el pensamiento del historiador y citando, ocasionalmente, frases a su vez citadas en estilo directo en el texto de origen. En ese sentido pueden servir de ejemplo algunos 
fragmentos del texto pastordista, en que describe el juicio, que luego aparecen asimilados en el discurso de Socobio:

\section{[Pastor Díaz]}

«En la refutación de los cargos, el defensor explanaba las razones del general; y viniendo luego al delito de que se le acusaba, lo examinaba bajo el aspecto político que tenía principalmente en aquel caso, y dirigía al Consejo estas alusivas palabras. '¿Quién podrá presentarse, en esta era de trastornos y continuos combates, como libre del delito de sedición, como limpio de la culpa que pesa sobre los conspiradores, como experto de la responsabilidad que gravita sobre los que en cualquier caso, y sea cualquiera la causa que los impulsase, han ocasionado trastornos a su patria?‘. Las miradas del defensor debieron estar clavadas como dardos en los jueces mientras pronunció estas terribles palabras. El general Capaz, el general Méndez Vigo, saldrían muy bien librados si sobre ellos no pesase más responsabilidad que las insurrecciones políticas y militares. [...] León no debía morir; el voto del presidente es siempre favorable al último de los reos, pero el presidente era el general Capaz; parece que el espectro de León le va persiguiendo por todas partes. El general Grases [...] exclamó dirigiéndose a sus compañeros al ver la sentencia: 'Si León ha de morir por haberse sublevado, ¿qué hacemos nosotros que no nos ahorcamos ahora mismo con nuestras fajas?'». (271)

\section{[Galdós: Socobio]}

«¡Buena está esa ley que todos han hollado! ¡La ley! ¡Del felpudo que han puesto como un guiñapo a fuerza de pisotones quiere hacer Espartero un inmaculado emblema de la Justicia!... El argumento empleado por Roncali en la defensa de León no tiene réplica, y fue como decir al Regente que no podía tirar la primera piedra. Y es de oro lo que dijo uno de los jueces, el general Grases: 'Si por sublevarse condenan a un hombre, ahorquémonos todos con nuestras fagas'. No le relato a usted el juicio porque carece de interés: la carta que encontraron a León y que éste no se cuidó de arrojar de sí le comprometía seriamente. Pero ¿qué importa todo esto? [...] No eran desleales, no eran traidores: cumplían un deber sagrado. Yo reconozco que Espartero, en su posición, siquiera ésta sea usurpada, no podía apreciar el caso del miso modo. Pero sobre el criterio estricto de la ley están el buen sentido y el principio cristiano que dice: 'O todos o ninguno'». (900-1)

De muy parecida manera transcribe Socobio la reacción de León después de la sentencia, añadiendo consideraciones de su cosecha:

\section{[Pastor Díaz]}

«La tranquilidad y la igualdad de ánimo que aquel hombre conservó en todo el discurso de sus últimas horas, causó admiración y aún sorpresa en los que no habían adivinado todas las grandes cualidades de su alma. [...] No obstante, la gravedad de su fisonomía y la templanza de sus palabras no se desmintieron sino en un momento. Estando escribiendo la carta para su mujer, arrojó repentinamente la pluma, se levantó con un movimiento nervioso, y descargando el puño sobre la mesa, exclamó con voz formidable: '¡Y he de morir yo!‘. La idea 
de su juventud malograda y de su ambición desvanecida, el sentimiento de la vida y de la fuerza, el recuerdo de su gloria, el amor y la orfandad de su familia, pasaron un momento por su imaginación y le arrancaron aquella exclamación terrible. Apaciguado aquel ímpetu, sólo se le volvieron a oír palabras de resignación y fortaleza». (272)

[Galdós: Socobio]

«Le vi por primera vez cuando acababa de confesar; le vi cuando mandó que rompieran en tres pedazos su lanza de combate; le vi cuando dijo con voz de trueno: ' $i Y$ he de morir yo!...' Le vi también resignado y tranquilo, platicando sosegadamente con Roncali; le vi y le hablé yo mismo, sin que pueda recordar ahora qué palabras comunes salieron de mis labios, ni descifrar las que él con tanta gravedad pronunció..., y turbado de ver tanta desdicha en quien merecía todas las venturas, y de considerar tan cerca del sepulcro al hombre más arrogante del Ejército español, al primer caballero del siglo, me salí despavorido, como el que presencia una grave alteración del orden de Naturaleza. El mundo se desquiciaba; tales abominaciones no podían pasar sin algún grave desconcierto en la máquina universal. Ausente de la capilla, vi a León tan grande, que los hombres en derredor suyo parecían hormigas. ¿Cómo podían matarle las hormigas, ni el feo y negruzco hormigón llamado Regente, por uno de estos artificios del lenguaje que usamos en nuestra república de insectos?» (901)

Del mismo modo se utiliza el texto final de la obra de Pastor Díaz, en que se recoge la muerte de León, bastante resumido aunque citando alguna de sus frases, con el distinto cierre del texto histórico, que tiene allí su punto final, y el novelesco, en que el narrador-personaje abandona el texto que ha seguido durante un tramo de su relación epistolar con el otro personaje destinatario, hasta ahora ausente del Episodio, pero conocido en la serie, Fernando Calpena.

\section{[Pastor Díaz]}

«Llegado el cortejo a la puerta de Toledo, el pueblo, al cual no se le permitió presenciar la ejecución de la sentencia, vio salir por ella a la víctima, para encontrarse a corta distancia dentro del cuadro. Al bajar del coche, el general León dijo al general Roncali, que parecía el verdadero reo: '¡Alma Federico! No es ocasión de abatirse'; y poniéndose la mano derecha en la visera del schakó, para oír la sentencia, le dijo al secretario de la causa, cuya voz embargaba un llanto tardío: 'No hay motivo para tanto, yo la leeré'. Abrazó luego al general Roncali; le abrazó por dos veces, diciéndole: 'Este abrazo para mi familia; y éste, para la de V.‘. Abrazó también al que había derramado los consuelos de la Religión en su alma; encaminose hacia el piquete, y tomando una actitud majestuosa, 'No tembléis — dijo a los granaderos-; jal corazón!. Dio las tres voces de mando, y cayó. ¡Aquellas eran las primeras heridas del general León, y aquel el día más terrible de la revolución española!» (274)

\section{[Galdós: Socobio]}

«No puedo pintarle a usted, señor de Calpena, mi impresión de piedad y espanto cuando León, a quien vi en aquel instante como si tocara el cielo con su cabeza, se plantó en actitud majestuosa ante los granaderos y les gritó: '¡No 
tembléis..., al corazón!‘ Oyéndole estoy todavía. ¡Qué voz!... Yo miré a todos lados. ¿No vendría en aquel instante algún emisario de Espartero trayendo el indulto? No, señor, no vino nadie... Huí despavorido... A no sé qué distancia oí la voz del General dando los gritos de mando... Todavía los oigo, ¡ay! Después la descarga. Huí más rápidamente [...]» (902)

Por último, se da un caso curioso, ejemplo máximo de la narrativización a que somete Galdós el texto histórico — sin duda teniendo en cuenta otras noticias concomitantes - de que en un momento dado, una alusión de Pastor Díaz se convierte en elementos narrativo entre los dos personajes narradores. Reelaborando el motivo de Diego de León como mártir que levantará adhesiones después de muerto, en el texto de Los Ayacuchos figura mostrarse cómo los dos personajes, Centurión y Socobio, han hablado entre ellos de la condena de León y cómo, cada uno por su cuenta, hacen llegar sus opiniones a Calpena, en forma de múltiple y cruzada citación. El simbolismo de los nombres y la caracterización de los personajes tienen un papel importante en relación a las ideas y simpatías de Galdós, que aun en tan insignificantes - o al menos secundarios - individuos de sus novelas se muestra tan atento a la hora de configurarlos; bien es verdad que toman, aunque sea ocasionalmente, el papel de narradores. Centurión (Centurio: fanfarrón), progresista bravucón que se come el mundo —en realidad, generoso; o al menos, incapaz de hacer daño- es el primero que desea salvar a León, prescindiendo de intereses políticos y personales; aunque para justificar su debilidad se apropie de la idea de Socobio con respecto al efecto de martirio en la aplicación de la última pena. Socobio (Serafín, pero no ángel: sólo su apariencia; y por tanto, ejemplar típico de los seres despreciables de Galdós) manifiesta su congoja en su habitual estilo dulzarrón y lacrimoso; pero no consigue dejar de alegrarse en su interior por el impulso que la muerte del general supondrá para la causa moderada. Cabe imaginar que también para el porvenir de su empleo en Palacio, aunque esto - dura cosa - ni siquiera lo mencione Socobio ni se le ocurra a Centurión. He aquí la secuencia:

\section{[Pastor Díaz]}

«había depuesto la arrogancia del general que había llamado a la muerte en los combates, por la majestad del mártir de una causa, del hombre cuyo duelo iba a llevar la España». (274)

[Galdós: Socobio]

«Acongojado escribo que no hubo perdón, y a ratos me pasa por la mente la terrible idea de que para los grandes fines españoles y humanos el no haber perdón ha sido provechoso, pues la causa que con víctimas de tal calidad se fortalece es causa ganada, y la que con tan torpe barbarie se envilece, causa perdida es». (901)

[Galdós: Centurión]

«Uno de mis compañeros en funciones palatinas, jovellanista rabioso, me ha dicho que se alegrará de que haya víctimas, porque el sentimiento popular las convertirá pronto en mártires y en el terreno del martirio germinará fácilmente la idea cristina, bien abonada con el parné, que lo hay, vaya si lo hay; 
[...] Como el gobierno sabe que en la Malmaison anhelan que aquí se castigue y que les hagamos víctimas y mártires, es seguro que a León y compañeros de locura no se les mandará rezar el Credo». (897) [...] «Apenas franqueada en el correo mi carta de ayer, llegó a mi noticia que don Diego de León ha sido condenado a muerte, y que mañana, jay dolor!, se ejecutará la terrible sentencia. Me apresuro a comunicárselo, y omito, por falta de tiempo, los comentarios que este grave suceso me sugiere. Aún tengo esperanza de que un acto de clemencia detenga la mano de la Justicia. Corren voces de indulto, y si viene, no seré yo de los últimos en aplaudirlo. Soy de los que piensan, mi buen don Fernando, que sería torpeza insigne dar al bando contrario la ventaja que supone una víctima como León. Lo que han perdido por su criminal atentado lo ganarían con la gran fuerza sentimental que ha de darles el martirio de un héroe. En fin, no soy yo quien ha de decidirlo y el señor Regente sabrá lo que más conviene al país y a la Libertad». (900)

El texto de Pastor Díaz ha cumplido su misión. Un capítulo, dramático y en cierta manera decisivo, de la historia de España, ha pasado al Episodio correspondiente: debidamente asimilado y narrativizado, desfigurado y diríase que despedazado entre los dos personajes narradores; porque muy otro, aunque es el mismo, era el texto en que Pastor Díaz volcó su admiración política y humana hacia Diego de León. Pero algo queda de su emoción y mucho de sus palabras en la relación de los hechos que Centurión y Socobio, lejos de la grandeza romántica, transmiten en sus cartas, desde su mentalidad y figura (no admirables: muy galdosianos) a su destinatario, Fernando Calpena. 
